\title{
INTERNATIONAL RESEARCH
}

\section{Is hiesho in pregnant women a risk factor for postpartum haemorrhage?}

\author{
Sachiyo Nakamura ${ }^{A, B}$ PhD, RN, CNM • Shigeko Horiuchi ${ }^{C} P h D, R N, C N M$
}

\author{
${ }^{\text {A Corresponding }}$ \\ Author: nakamura@ \\ yokohama-cu.ac.jp \\ ${ }^{\text {B } Y o k o h a m a ~}$ \\ City University, \\ Yokohama, Japan \\ ${ }^{\mathrm{C}}$ St. Luke's College \\ of Nursing and St. \\ Luke's Birth Clinic, \\ Tokyo, Japan
}

\begin{abstract}
Background: In Japanese culture, a cold sensation known as "hie" is an important symptom in traditional medicine. Hiesho is a condition whereby the sympathetic nervous system becomes dominant, causing peripheral blood vessels to contract, impairing circulation and leading to low skin temperatures in the extremities. A link between hiesho and prolonged labour and uterine inertia, both of which are risk factors for postpartum haemorrhage (PPH), has previously been identified.
\end{abstract}

Aim: The aim of this study was to analyse whether hiesho has a direct impact on PPH by comparing the outcomes for women who experienced hiesho in their pregnancies with those who did not.

Methods: The study design was a retrospective cohort study conducted over 12 months, between 19th October, 2009, and 8th October, 2010, involving 2,427 women who had given birth in six hospitals in Japan. Women were excluded if they had had a caesarean section. Data were extracted from medical records and a paper questionnaire. Analysis was conducted using multiple logistic regression analysis and the Mantel-Haenszel test.

Findings: Of the women, 613 experienced PPH (25.3\% of the entire sample), of whom 343 (56.0\%) had experienced hiesho. In the analysis of covariance, the regression coefficient for hiesho was 0.2 , $\mathrm{p}=0.07$, the odds ratio $(\mathrm{OR})$ was 1.22 , and the $95 \%$ confidence interval $(\mathrm{CI})$ was $0.98-1.50$. In a stratified analysis, the regression coefficient was $0.25, \mathrm{p}=0.02$, the common OR was 1.29 , and $95 \%$ CI was 1.04-1.59. Thus, there was no significant link found between a woman experiencing heisho during pregnancy and having a $\mathrm{PPH}$.

Conclusion: Although the findings indicate that uterine inertia and prolonged labour are direct causes of PPH, hiesho may potentially have an indirect effect. Therefore, since hiesho potentially affects the occurrence of uterine inertia and prolonged labour, preventing hiesho may help avoid uterine inertia and prolonged labour and consequently PPH. For women who experience hiesho in pregnancy, lifestyle activities known to improve peripheral circulation should be promoted antenatally.

Keywords: pregnant woman, postpartum haemorrhage (PPH), risk factor, hiesho (sensitivity to cold)

\section{INTRODUCTION}

In Japanese culture, a cold sensation known as "hie" is an important symptom in traditional medicine. Hiesho is considered to be a condition in which the sympathetic nervous system becomes dominant, resulting in poor circulation in the extremities due to contraction of the peripheral blood vessels. In Nakamura, Ichisato, Horiuchi, Mori, and Momoi's (2011) analysis of the concept of hiesho, it is defined as a condition in which "there is a difference between core temperature and peripheral temperature and a delay in the rise of the peripheral temperature even when the individual is in a warm environment, resulting in a 'chilly feeling' in many cases" (p.2).

In Western medicine, hiesho is an unfamiliar concept but, in Oriental medicine, it is recognised as an important symptom of potential health problems. According to Yoshino et al. (2013), hiesho is a common phenomenon in Japanese and traditional Chinese medicine; it is recognised as a condition that requires diagnosis and treatment. Hiesho is commonly experienced by
Japanese pregnant women, with one study reporting 67\% of pregnant women experienced hiesho (Nakamura, 2008). Pregnant women with hiesho have cold hands and feet all day, which is not only uncomfortable but is also a condition that exacerbates minor problems during pregnancy, such as early uterine contractions, headache or lower back pain.

Although the concept of hiesho does not exist in Western medicine, research conducted among pregnant Brazilian women living in Brazil revealed that $57 \%$ of the women in that study experienced hiesho (Nakamura et al., 2011). Pregnant women in the Philippines were also studied and, although those participants were not aware of experiencing hiesho as such, they had experienced cold hands and feet (Takeuchi \& Nakamura, 2018). In other words, the issue is that awareness of hiesho, as a standalone symptom, is weak and we suggest that hiesho possibly exists in countries other than Japan.

Nakamura and Horiuchi (2013) found a relationship between hiesho, a physical state in pregnant women, and prolonged 
labour and uterine inertia. Both of these conditions are known risk factors for postpartum haemorrhage (PPH). In their study among pregnant women aged 35 to 39, with and without hiesho, the probability of uterine inertia was 2.9 times (OR 2.94), and of prolonged labour 2.6 times (OR 2.56), higher in the group with hiesho. Among pregnant women aged 40 and over, the probability of uterine inertia was 7 times (OR 7.02), and of prolonged labour 7 times (OR 7.19), higher among those with hiesho. From this, we deduced that uterine inertia and prolonged labour may occur more often in pregnant women with hiesho.

Simple lifestyle modifications and complementary therapies can reduce the prevalence of hiesho. In one study, a group of pregnant women with hiesho in the latter half of pregnancy, who followed a four-week programme involving wearing leg warmers, performing exercises and pressing acupressure points, experienced a statistically significant rise in temperature in their extremities compared to the control group (Nakamura \& Horiuchi, 2017).

$\mathrm{PPH}$ can be a serious complication following labour, in some instances putting the woman's life in danger. Therefore, it is urgent that efforts are made to identify predictor factors for this condition. Uterine inertia and prolonged labour are both risk factors for PPH. Other risk factors include multiple births and induced labour (Cunningham, Leveno, \& Bloom, 2014).

Active management in placental delivery is advocated by the International Confederation of Midwives (ICM) and the International Federation of Gynecology and Obstetrics (FIGO) to prevent PPH (ICM \& FIGO, 2006). The New Zealand College of Midwives (NZCOM) also recommends that, when there is a risk of PPH, active management is the first choice in dealing with the third stage of labour, requiring administration of an oxytocic drug following the birth of the baby (NZCOM, 2013). According to the National Institute for Health and Care Excellence (NICE) delivery guidelines (2014), active management compared to physiological management can help reduce a PPH of over $1,000 \mathrm{ml}$. However, the use of oxytocic drugs has been reported to have side effects, such as higher diastolic blood pressure, vomiting after delivery and afterpains.

Given these findings, we began this study to determine if hiesho in pregnancy was also associated with $\mathrm{PPH}$. Thus, our aim was to analyse the direct impact of hiesho on $\mathrm{PPH}$ by comparing blood loss outcomes of pregnant women with and without hiesho in pregnancy.

\section{Operational definition of terms}

An objective indicator of hiesho is a large difference between core body and peripheral temperatures. In previous studies, the forehead temperature of pregnant women with hiesho was $36.2^{\circ} \mathrm{C}$, compared to $36.4^{\circ} \mathrm{C}$ among pregnant women without hiesho, which was not a significant difference. However, the sole temperature was $31.2^{\circ} \mathrm{C}$ in women with hiesho and $33.9^{\circ} \mathrm{C}$ in those without, showing a significant difference between the two groups. Furthermore, the combined difference in temperature was significant $\left(5.5^{\circ} \mathrm{C}\right.$ vs. $\left.2.4^{\circ} \mathrm{C}\right)$ between those with and those without hiesho (Nakamura, 2008). A similar result was obtained for skin temperature. Participants' body temperatures were measured using Core Temp R CTM-205, with proven reliability and validity. Core and skin temperatures were measured simultaneously, and the results had strong reliability and validity.

As the results of prior studies show that being conscious of cold reflects a statistically significant difference in forehead and sole temperatures, women in the latter half of pregnancy who had cold hands and feet in daily life were deemed to have hiesho (Nakamura, 2008).

\section{METHOD}

The research design was a case-control study. Data were collected over a 12-month period during 2009 and 2010, with research being conducted in six general hospitals in Japan. A uniform practice among the hospitals in measuring blood loss during birth, including blood loss up to two hours after birth, was to not only measure clots but also estimate blood on gauze or sheets (except amniotic fluid). No significant differences in measurement values were found between institutions.

\section{Study participants}

The participants in the present study were Japanese women in hospitals who had given birth within the previous four days. Women who had had a caesarean section or who were experiencing unstable physical or mental health conditions were excluded from the study.

\section{Data collection}

In this study, data were extracted from medical records and a questionnaire was circulated to participants. The questionnaire included a question as to whether the participant had developed hiesho in the latter half of pregnancy, along with other questions relating to demographic data, which included the woman's age, labour and birth history, smoking history, and any complications and abnormalities during pregnancy. Information on participants' condition at birth (number of weeks of pregnancy, length of time from the initiation of labour to birth, uterine inertia, prolonged labour, condition of newborn, etc.) and whether $\mathrm{PPH}$ had developed was extracted from the medical records (Table 1).

Anxiety during the latter part of pregnancy increases stress, and stress heightens the action of the sympathetic nervous system. Anxiety and stress, which are confounding factors for hiesho, were measured using the Stress Response Scale-18 (SRS-18) for psychological stress reactions. The related questionnaire asked participants after the birth to recall how they had felt during the latter stage of their pregnancies (Suzuki, Shimada, Sakano, Fukui, $\&$ Hasegawa, 2007). The questionnaire consisted of 18 questions, with answers ranging from 1 (completely disagree) to 4 (completely agree) on a 4-point Likert scale. Total scores obtained were converted into four stages by using a score conversion table. The discriminant validity of the concepts was tested, and Cronbach's alphas were obtained for the stress scale (0.91) and anxiety scale (0.84), demonstrating no issues with internal consistency and confirming the high reliability of the questionnaire.

\section{Methodology}

Participants were recruited by having staff in the maternity wards of six general hospitals in Japan identify women who met the inclusion criteria. Prior to the researchers gaining access to participants, hospital staff confirmed that they were willing to participate, after which the researchers also asked participants if they wished to be included in the research. After they had confirmed their intent to participate, the researchers explained to participants, both verbally and in writing, that participation in this study was voluntary, that submitting the completed questionnaire was deemed to imply written consent to participate, and that all data collected would be used only for the purposes of this study. The study was approved by the Ethics Committee of the University (24th September, 2009: 09-057) and by the ethics committees of the six institutions where the study was conducted (approval no. 1003).

The research study was described to the prospective participants and they were handed the questionnaire. The women were asked 
to place completed questionnaires in a retrieval box provided for that purpose. The researchers collected the completed questionnaires and extracted data about labour and birth from the medical records of the women who had chosen to participate. To establish matching between the questionnaire and medical records, participants were asked to enter the date and time of birth (delivery number) and the birthweight of the newborn; these were matched with the details in the medical records. When the data were extracted, only the information required for the study was recorded and the women's names were not included.

\section{Table 1. Baseline characteristics of participants}

Characteristic

mean $\pm S D / N$

No. \%

Age

$32.5 \pm 4.6$

Parity

Primipara $\quad 1,294 \quad 53.3$

Multipara $\quad 1,133 \quad 46.7$

Smoking (during pregnancy)

Sensitivity to cold (hiesho)

Complications (perinatal periodrelated primary disease)

Complications prior to this pregnancy

Abnormalities during pregnancy (disorder developing during pregnancy)

Number of weeks of pregnancy (mean $\pm S D$ )

Mode of birth

Forceps/

vacuum

delivery

Length of time for labour and birth (h) (mean $\pm S D$ )

Blood loss at birth (ml) (mean \pm SD)

Weak labour pains - labour inertia

Prolonged labour (when the baby is not born 30 hours after onset of labour for a primipara or 15 hours for a multipara)

Atonic postpartum haemorrhage

Number of births (mean $\pm S D$ )

Apgar score at 1 minute (mean $\pm S D$ )

Apgar score at 5 minutes (mean \pm SD)

Birthweight (g)

$n=2,427$

\section{Data Analysis}

Statistical analysis was conducted using the SPSS Statistics software versions 17.0 and 19.0. Data from the two groups, pregnant women with hiesho and those without hiesho, were analysed to determine any relationship between hiesho and $\mathrm{PPH}$.

Considering the connection between independent and dependent variables, the influence of confounding factors must be excluded when studying whether there is any relationship between factors and results. Therefore, in this study, propensity scores were used to adjust for confounding factors, other than PPH, in both the hiesho and non-hiesho groups (Hoshino \& Okada, 2006; Rosenbaum $\&$ Rubin, 1983). Thus, in observational studies, propensity scores enable the aggregation of multiple confounding factors into one variable_-similar to the process of "pseudo-analysis" of observational study data, such as that in randomised controlled trials (Cepeda, Boston, Farrar, \& Strom, 2003; Drake, 1993).

In this study, we selected confounding factors for hiesho and PPH to calculate propensity scores. For PPH, we selected factors from domestic and overseas medical literature believed to affect $\mathrm{PPH}$ and used a panel of experts to study their internal validity. From all factors extracted from the medical notes, we selected those showing a statistically significant difference for presence or absence of PPH. Regarding hiesho, out of all the factors extracted, we selected those showing a statistically significant difference for presence or absence of hiesho. We ultimately selected 16 confounding factors (Table 2), making hiesho a dependent variable (response variable), and applied multiple logistic regression analysis to a selected covariance as independent variables (explanatory variables) to calculate propensity scores. Results showed that eight of the factors included in the model equation-smoking during pregnancy, the presence of ovarian cysts, strategies for relieving hiesho during labour and birth, fatigue during labour and birth, stress during the latter half of pregnancy, uterine inertia, prolonged labour, and abnormalities during labour and birth-were involved, and the propensity scores calculated averaged 0.42 (standard deviation [SD] 0.15; Table 3).

\section{Table 2. Factors identified as a covariance}

Factor
Maternity history (number of births, including this one)
Complications of ovarian cystoma
Chorioamnionitis
Use of tocolytics during pregnancy
Fatigue during labour and birth
Care for relieving hiesho during labour and birth
Stress during latter half of pregnancy
Use of uterotonics/oxytocin ( 1 st and 2 nd stages of labour)
Length of time of labour and birth
Perineal laceration
Use of oxytocics (3rd stage of labour)
Interventions during labour and birth
Uterine dystocia
Prolonged labour
Macrosomia

Next, we applied a multiple logistic regression analysis to calculate propensity scores and later used a logistic regression analysis to analyse the effect of propensity scores before adjustment for hiesho. By using the propensity scores thus calculated, we gave weight to background factors other than PPH (confounding factors) in the hiesho and non-hiesho groups, so that they would be identical in both groups through analysis of covariance and stratified analysis, and we calculated the effect of hiesho on PPH after adjustment for propensity scores.

In the stratified analysis, participants were evenly divided into five subgroups, according to the propensity score values calculated. Next, a chi square test for the two variables of hiesho and PPH was conducted for each subgroup, and the results were combined, yielding a regression coefficient of common OR and a 95\% CI. A stratified analysis was conducted according to the Mantel-Haenszel method. In the stratified analysis, it is desirable to have at least five subgroups (Rubin, 1997); therefore, the minimum and maximum 


\begin{tabular}{|c|c|c|c|c|c|c|c|}
\hline Covariance & $\begin{array}{l}\text { Regression } \\
\text { coefficient (B) }\end{array}$ & Standard error (SE) & Wald statistics & $\begin{array}{l}\text { Degree of } \\
\text { freedom }\end{array}$ & $\begin{array}{l}\text { Significance } \\
\text { probability }(p)\end{array}$ & $\begin{array}{l}\text { Odds } \\
\text { ratio (OR) }\end{array}$ & $\begin{array}{l}95 \% \\
\text { confidence } \\
\text { interval }(\mathrm{Cl})\end{array}$ \\
\hline Smoking during pregnancy & 0.53 & 0.24 & 4.90 & 1 & 0.03 & 1.69 & $1.06-2.70$ \\
\hline Ovarian cystoma & 0.42 & 0.21 & 3.94 & 1 & 0.05 & 1.52 & $1.01-2.30$ \\
\hline $\begin{array}{l}\text { Care for relieving hiesho during } \\
\text { labour and birth }\end{array}$ & 0.38 & 0.08 & 21.80 & 1 & $<0.001$ & 1.46 & $1.25-1.71$ \\
\hline Fatigue during labour and birth & -0.13 & 0.05 & 5.36 & 1 & 0.02 & 0.88 & $0.79-0.98$ \\
\hline Stress during latter half of pregnancy & 0.02 & 0.01 & 16.08 & 1 & $<0.001$ & 1.02 & $1.01-1.03$ \\
\hline Uterine inertia & 0.43 & 0.15 & 8.15 & 1 & 0.004 & 1.54 & $1.14-2.06$ \\
\hline Prolonged labour & 0.51 & 0.20 & 6.63 & 1 & 0.01 & 1.66 & $1.13-2.44$ \\
\hline Interventions during labour and birth & 0.82 & 0.09 & 76.06 & 1 & $<0.001$ & 2.27 & $1.89-2.73$ \\
\hline
\end{tabular}

Goodness of fit of the model: chi square test $p<.0 .001$, Nagelkerke $R^{2} .13$, Hosmer-Lemeshow test $p=0.90$, Accuracy of discrimination $64.4 \%, n=2,427$

values obtained for each propensity score were distributed evenly across the five subgroups (Rosenbaum \& Rubin, 1984).

\section{FINDINGS}

A total of 2,821 women were recruited. Of these, 11 individuals were excluded: three because they were non-Japanese and eight beacause they declined to give permission for access to their medical records. An additional 383 women who had delivered via caesarean section were also excluded, giving a final total of 2,427 participants (63.4\% retrieval rate, $86 \%$ valid response rate).

\section{Participant characteristics}

Participants ranged in age from 16 to 45, with an average age of 32.5 (SD 4.6; Table 1). Of the total cohort, 1,408 (58\%) reported experiencing hiesho during pregnancy, while 1,019 (42\%) had not. From the total sample, 613 respondents $(25.3 \%)$ had experienced PPH.

Regarding smoking during pregnancy, 82 women (3.4\%) had smoked during pregnancy, while 2,345 women (96.6\%) had not. Complications occurred in 905 women (37.3\%) and included infertility $(\mathrm{n}=237,9.8 \%)$, uterine fibroids $(\mathrm{n}=205,8.4 \%)$ and ovarian cysts $(\mathrm{n}=104,4.3 \%)$. Complications during pregnancy included breech presentation $(\mathrm{n}=417,17.2 \%)$ and anaemia $(\mathrm{n}=923,38 \%)$, and complications during labour included uterine inertia $(n=272,11.2 \%)$ and prolonged labour $(n=146,6 \%)$.

\section{Relationship between presence/absence of hiesho and PPH}

Of the 613 respondents (25.3\%) who had experienced PPH, 343 (56\%) reported experiencing hiesho and 270 (44\%) reported not experiencing hiesho.

\section{Choice of confounding factors and calculation of propensity scores}

To calculate propensity scores, confounding factors for hiesho and $\mathrm{PPH}$ were selected. Results showed that the eight factors included in the model equation were involved, and propensity scores calculated averaged 0.42 (SD 0.15; Table 3). These eight factors were thus found to be confounding factors that affected the relationship between hiesho and PPH. The propensity score of 0.42 demonstrates identical weighting of the group of women with hiesho and the group of those without hiesho.

\section{Impact of hiesho on PPH}

The results obtained for the impact of hiesho on $\mathrm{PPH}$, before adjustment using propensity scores, were a regression coefficient of 0.76 and $\mathrm{p}<0.001$ (OR 2.13; 95\% CI, 1.77-2.57; Table 4), indicating that the probability of $\mathrm{PPH}$ was 2.13 times higher among pregnant women with hiesho than those without hiesho, a statistically significant difference.

However, when the impact of hiesho on PPH was adjusted using the propensity scores, the regression coefficient was 0.2 and $\mathrm{p}=0.07$ (OR 1.22; 95\% CI, 0.98-1.50). Using propensity scores to adjust for the impact of confounding factors, the probability of $\mathrm{PPH}$ was 1.22 times higher among the women who experienced hiesho in the latter half of their pregnancy. This is not a statistically significant difference. The evaluation of the model, using the chi square value omnibus tests of model coefficients was 444.62, $\mathrm{p}<0.001$, indicating that the goodness of fit of the model was high. The accuracy of discrimination was $72.9 \%$, giving the model sufficient predictability.

For the stratified analysis, respondents were evenly divided into five subgroups, according to the propensity score values calculated,

Table 4. Probability of atonic postpartum haemorrhage due to hiesho

\begin{tabular}{|c|c|c|c|c|c|c|c|c|c|}
\hline & & & $\begin{array}{l}\text { Regression } \\
\text { coefficient } \\
\text { (B) }\end{array}$ & $\begin{array}{l}\text { Standard } \\
\text { error (SE) }\end{array}$ & $\begin{array}{l}\text { Wald } \\
\text { statistics }\end{array}$ & $\begin{array}{l}\text { Degree of } \\
\text { freedom }\end{array}$ & $\begin{array}{l}\text { Significance } \\
\text { probability } \\
\text { (p) }\end{array}$ & $\begin{array}{l}\text { Odds ratio } \\
\text { (OR)/ } \\
\text { common } \\
\text { odds ratio }\end{array}$ & $\begin{array}{l}95 \% \\
\text { confidence } \\
\text { interval }(\mathrm{Cl})\end{array}$ \\
\hline \multirow[t]{2}{*}{$\begin{array}{l}\text { After adjustment with } \\
\text { propensity scores }\end{array}$} & $\begin{array}{l}\text { Analysis of } \\
\text { covariance }^{* *}\end{array}$ & Hiesho & 0.20 & 0.11 & 3.29 & 1 & 0.07 & 1.22 & $0.98-1.50$ \\
\hline & $\begin{array}{l}\text { Mantel- } \\
\text { Haenszel }\end{array}$ & Hiesho & 0.25 & 0.11 & 5.12 & 1 & 0.02 & 1.29 & $1.04-1.59$ \\
\hline
\end{tabular}

Goodness of fit of the model: $n=2,427$

*chi square test $p<0.001$, Nagelkerke $\mathrm{R}^{2} .04$, accuracy of discrimination $74.7 \%$

** chi square test $p<0.001$, Nagelkerke $R^{2} .25$, Hosmer-Lemeshow test $p<0.001$, accuracy of discrimination $72.9 \%$ 
and a chi square test for the two variables of hiesho and PPH was conducted for each subgroup. The results were combined, yielding a regression coefficient of a common OR and 95\% CI. Stratified analysis was conducted according to the Mantel-Haenszel method. The results were a regression coefficient of 0.25 and $\mathrm{p}=0.02$ (common OR 1.29; 95\% CI, 1.04-1.59, managing not to cross 1). Using propensity scores to adjust the impact of confounding factors, the probability of $\mathrm{PPH}$ was 1.29 times higher among the women who experienced hiesho in the latter half of pregnancy. While this was a significant difference, the value was very close to that obtained in the analysis of covariance.

Essentially, if the impact of confounding factors is not taken into account, the probability of PPH among women with hiesho is 2.13 times greater, a statistically significant difference; however, when propensity scores are used to exclude the impact of confounding factors, the difference is not statistically significant.

\section{DISCUSSION}

\section{Relationship between hiesho in pregnancy and PPH}

The aim of this study was to determine whether hiesho is a risk factor for PPH. We found that, although PPH occurred 1.2 to 1.3 times more frequently in pregnant women with hiesho in the latter half of pregnancy than in those without hiesho, a considerable covariant overlap was observed, indicating that hiesho had little impact on the overall risk of PPH.

We used propensity scores to adjust for important confounding factors. Prior to making this adjustment, we found that pregnant women with hiesho were 2.1 times more likely to experience PPH than those without hiesho ( $\mathrm{p}<0.001$; OR 2.13 ; 95\% CI, 1.77 2.57). This demonstrates that confounding factors have an impact on the relationship between hiesho and PPH and that factors other than hiesho were likely the major causes of PPH.

Normally, after the birth of the baby and delivery of the placenta, the cavity of the uterus empties and uterine contractions reduce blood loss by the biological ligation provided by the uterine muscle. When this function is impaired, $\mathrm{PPH}$ can occur (Cunningham et al., 2014). Thus, the presence of ovarian cysts or uterine fibroids can interfere with this normal physiological process (Cunningham et al., 2014). In this study, $8.4 \%$ of the respondents had uterine fibroids and $4.3 \%$ had ovarian cysts, both of which were considered as predisposing factors for $\mathrm{PPH}$.

Smoking during pregnancy was also a confounding factor (Cunningham et al., 2014). It is known that one of the physical effects of the nicotine contained in cigarettes is to constrict peripheral blood vessels. Thus, smoking may aggravate hiesho.

Labour is the contraction of the smooth muscle of the uterus, and insufficient contraction can contribute to uterine inertia and prolonged labour (Cunningham et al., 2014). The relationship between hiesho, uterine inertia and prolonged labour found by Nakamura and Horiuchi (2013) suggests that the presence of hiesho is a risk. Our hypothesis was that because hiesho is a condition where the sympathetic nervous system becomes dominant and one of the effects of the sympathetic nervous system is to cause the smooth muscle to relax, this may lead to increased risk of PPH. However, this is not supported by our data.

Although we have found that uterine inertia and prolonged labour are direct causes of PPH, hiesho may potentially have an indirect effect. Therefore, as hiesho potentially affects the occurrence of uterine inertia and prolonged labour, preventing hiesho may help avoid uterine inertia and prolonged labour and consequently PPH.
Hiesho can be mediated through complementary therapies, such as wearing leg warmers, performing exercises and pressing acupressure points (Nakamura \& Horiuchi, 2017). It is possible that introducing these interventions may help prevent uterine inertia and prolonged labour, potentially contributing to a reduction in the incidence of $\mathrm{PPH}$.

\section{STRENGTHS AND LIMITATIONS}

This study is the first of its kind to systematically examine hiesho and its relationship to PPH. As such, it contributes to the field of research related to hiesho.

The limitation of this study is that it targeted only Japanese women living in Japan and the findings may not be applicable to women in other countries. In clinical midwifery practice in Japan, midwives evaluate hiesho by palpation and recommend that pregnant women keep warm and take walks regularly (Gepshtein, Horiuchi, \& Eto, 2007). Today, many Asian women live and give birth all over the world and New Zealand has a growing Asian community. We believe it is important to disseminate information from Japan concerning the concept and potential implications of hiesho on childbirth for these women in particular.

\section{CONCLUSION}

Hiesho is an important facet of Japanese culture that can influence health. Hiesho during pregnancy is linked to uterine inertia and prolonged labour. Both of these conditions can lead to PPH. This retrospective cohort study analysed the impact of hiesho on PPH for 613 pregnant women experiencing or not experiencing hiesho. Findings indicate that hiesho has no direct impact on PPH. However, there may be a secondary influence increasing the likelihood of uterine inertia and prolonged labour. Therefore, it is suggested that managing hiesho may help avoid uterine inertia and prolonged labour and, potentially, reduce the incidence of $\mathrm{PPH}$ in susceptible women. In clinical practice, we encourage midwives to diagnose hiesho by palpating pregnant women's hands and feet and provide care by recommending that pregnant women keep warm, exercise and stimulate circulation in their hands and feet.

\section{ACKNOWLEDGEMENTS \& CONFLICTS OF INTEREST DISCLOSURE}

The authors express their gratitude to the respondents and to the staff of the cooperating institutions who participated in this study. This research was undertaken with the help of Grant-in-Aid for Scientific Research No. 22592525 from the Japan Society for the Promotion of Science (JSPS) and presented before the Kanagawa Society of Maternal Health, Japan.

The authors declare that they have no conflicts of interest with respect to this research manuscript.

\section{REFERENCES}

Cepeda, M.S., Boston, R., Farrar, J.T., \& Strom, B.L. (2003). Comparison of logistic regression versus propensity score when the number of events is low and there are multiple confounders. American Journal of Epidemiology, 158(3), 280-287. https://doi.org/10.1093/aje/ kwg1 15

Cunningham, F.G., Leveno, K.J., \& Bloom, S.L. (2014). Williams Obstetrics (24th ed.). New York, USA: McGraw-Hill Medical.

Drake, C. (1993). Effects of misspecification of the propensity score on estimators of treatment effect. Biometrics, 49(4), 1231-1236. Retrieved from http://www.jstor.org/stable/2532266

Gepshtein, Y., Horiuchi, S., \& Eto, H. (2007). Independent Japanese midwives: A qualitative study of their practise and beliefs. Japan Journal of Nursing Science, 4(2), 85-93. https://doi.org/10.1111/j.17427924.2007.00078.x 
Hoshino, T., \& Okada, K. (2006). Estimation of causal effect using propensity score methods in clinical medicine, epidemiology, pharmacoepidemiology and public health: A review. Journal of the National Institute of Public Health, 55, 230-243.

International Confederation of Midwives (ICM) and International Federation of Gynecology and Obstetrics (FIGO). (2006). Prevention and treatment of post-partum haemorrhage: New advances for low resource settings. Retrieved from http://www.who.int/pmnch/ events/2006/figo2006statementeng.pdf

Nakamura, S. (2008). Sensitivity to cold in pregnant women: Characteristics of skin temperature and its relationship to daily life. Journal of Japan Academy of Nursing Science, 28(1), 3-11. https://doi. org/10.5630/jans.28.1_3

Nakamura, S., \& Horiuchi, S. (2013). Relationship between advanced maternal age, hiesho (sensitivity to cold) and abnormal delivery in Japan. The Open Nursing Journal, 7, 142-148. https://doi. org/10.2174/1874434601307010142

Nakamura, S., \& Horiuchi, S. (2017). Randomized controlled trial to assess the effectiveness of a self-care program for pregnant women for relieving hiesho. The Journal of Alternative and Complementary Medicine, 23(1), 53-59. https://doi.org/10.1089/acm.2016.0030

Nakamura, S., Ichisato, S.M., Horiuchi, S., Mori, T., \& Momoi, M. (2011). Pregnant women's awareness of sensitivity to cold (hiesho) and body temperature observational study: A comparison of Japanese and Brazilian women. BMC Research Notes, 4(1), 278. https://doi. org/10.1186/1756-0500-4-278

National Institute for Health and Care Excellence (NICE). (2014). Intrapartum care for healthy women and babies. Retrieved from https:// www.nice.org.uk/guidance/cg190/

New Zealand College of Midwives. (2013). Consensus Statement: Facilitating the Birth of the Placenta. Retrieved from https://www. midwife.org.nz/quality-practice/nzcom-consensus-statements

Rosenbaum, P.R., \& Rubin, D.B. (1983). Assessing sensitivity to an unobserved binary covariate in an observational study with binary outcome. Journal of the Royal Statistical Society. Series B (Methodological), 45(2), 212-218. Retrieved from http://www.jstor.org/stable/2345524

Rosenbaum, P.R., \& Rubin, D.B. (1984). Reducing bias in observational studies using subclassification on the propensity score. Journal of the American Statistical Association, 79(387), 516-524. Retrieved from http:// www.jstor.org/stable/2288398

Rubin, D.B. (1997). Estimating causal effects from large data sets using propensity scores. Annals of Internal Medicine, $127(8$ Part 2), 757. https://doi.org/10.1059/0003-4819-127-8_Part_2-199710151-00064

Suzuki, S., Shimada, H., Sakano, Y., Fukui, I., \& Hasegawa, M. (2007). SRS-18 psychological stress reaction measurement scale. Tokyo, Japan: Kokoro Net Co. Ltd.

Takeuchi, S., \& Nakamura, S. (2018). Awareness of hiesho among Filipino pregnant women and features of their daily activity. Kanagawa Society of Maternal Health, 21(1), 21-27.

Yoshino, T., Katayama, K., Munakata, K., Horiba, Y., Yamaguchi, R., Imoto, S., ...Watanabe, K. (2013). Statistical analysis of hie (cold sensation) and hiesho (cold disorder) in kampo clinic. Evidence-Based Complementary and Alternative Medicine, 2013, 398458. https://doi. org/10.1155/2013/398458

\section{Accepted for Publication July 2018}

Nakamura, S., \& Horiuchi, S. (2018). Is hiesho in pregnant women a risk factor for postpartum haemorrhage? New Zealand College of Midwives Journal, 54, 38-43.

https://doi.org/10.12784/nzcominl54.2018.5.38-43 